\title{
Correlation Oxygen Saturation in Pulse Oximetry With Partial Pressure Oxygen in the Arteries (Pao2) on Blood Gas Analysis Examination in Patient Hypovolemic Shock
}

\author{
Susi Sembiring* \\ *Departement of Anaesthesiology and Intensive Therapy, Faculty of Medicine, HKBP Nommensen University, Medan, Indonesia
}

Abstract:-

\section{$>$ Background:}

Determination of oxygenation status is very important in hypovolemic shock patients treatment, oxygenation status can be seen in the patient's clinical sign and examination of $\mathrm{SpO} 2$ and $\mathrm{PaO2}$. $\mathrm{PaO2}$ examination is a gold standard but has the disadvantage of less available and invasive, while $\mathrm{SpO2}$ by Pulse Oximeter is easy to do, this research try to determine the correlation between $\mathrm{SpO} 2$ pulse oximeter and $\mathrm{PaO} 2$ on blood gas analysis.

\section{$>$ Methods:}

This research is Cross Sectional analytics, the subject of this research were 39 hypovolemic shock patients admitted to Emergency Room RSU DR Pirngadi Medan between October 2019 - February 2020, correlation between $\mathrm{SpO2}$ (pulse oximeter) - PaO2 (blood gas) were measured by Pearson Correlation .

\section{$>$ Result:}

$O$ The name of this article is: $f$ the 39 samples 41.8\% 40-60 years, 30 (76.9\%) with systolic under 100 at admission to the ER, $16(41 \%)$ came with hypoxic conditions $\mathrm{SpO} 2<93 \%$. Mean difference of $\mathrm{SpO} 2$ was 4.6 points lower than $\mathrm{SaO2}$ blood gas, and 5.2 points lower at systolic $<100 \mathrm{mmHg}$, lower 5.6 points $<90$ mmHg. In the Pearson SpO2 - PaO2 Correlation test in systolic $<100 \mathrm{mmHg}$ obtained correlation $(\mathrm{r}=0.423 ; \mathrm{p}=$ $0.020)$ and in systolic $<90 \mathrm{mmHg}(r=0.411 ; p=0.04)$.

\section{Conclusion:}

The name of this article is: Clinicians are expected to wisely assess the $\mathrm{SpO2}$ results in Hypovolemic Shock patients where there are lower grades of 4.6 - 5.6 points, we found correlation between $\mathrm{SpO2}$ - $\mathrm{PaO} 2$ in hypovolemic shock conditions.

Keywords:- Hypovolemic Shock, SpO2, PaO2.

\section{INTRODUCTION}

Hypovolemic shock is a condition of decreased oxygen perfusion to tissues due to loss of blood or body fluids, at an advanced stage it will cause organ ischemia and multi-organ failure to death. ${ }^{1}$. Fluid resuscitation and monitoring of oxygenation status are the main measures to avoid mortality ${ }^{2}$ Blood gas analysis is one of the standard tests in hypovolemic shock patients to assess the partial pressure of oxygen $\mathrm{PaO} 2$ in the blood. ${ }^{2}$ However, this examination is difficult because of collapsed blood vessels in shock, the patient is anxious due to hypoxia, and the relative length of time these results have been obtained, this is further complicated by this facility that is not available in primary health services or in hospitals in remote areas, while the Pulse Oximeter is a simple tool. , easy to obtain and not invasive but can only detect levels of Oxygen $\mathrm{SpO} 2$. This condition raises the question whetherSpO2 on Pulse Oximeter can assess the degree of partial pressure of Oxygen in blood $\mathrm{PaO} 2$ or not. ${ }^{3,4}$

In this study trying to assess the correlation of Oxygen Saturation on Pulse oxymetry with partial pressure of oxygen in the arteries, if there is a significant correlation, then this study can be continued or developed to predict the value of arterial oxygen partial pressure by assessing its sensitivity and specificity so that in the future it can be a very useful supporting tool, especially in hospitals. peripheral with limited Blood Gas Analyzers. ${ }^{5}$

\section{METHODS}

This study is a cross sectional study which is an observational epidemiological study. This study examines the correlation between oxygen saturation on the pulse oximeter and the value of partial pressure of oxygen in the arteries $(\mathrm{PaO} 2)$ in patients with hypovolemic shock. The research was carried out after passing e The name of this article is: thical clearance from Research ethics commission in the field of health, Faculty of Medicine, University of HKBP Nommensen / RSUD DR Pirngadi Medan, the case sample is all members of the case population who entered the Emergency Unit of the Pirngadi Hospital Medan with a diagnosis of hypovolemic shock between October 2019 February 2020, the total sample was 39 patients. Diagnosis of hypovolemic shock is confirmed by clinical criteria: history of fluid or blood loss (in cases of trauma), systolic 
ISSN No:-2456-2165

pressure, respiration, pulse, consciousness, peripheral perfusion and urine volume according to the 4 degrees of hypovolemic shock distribution. The inclusion criteria were: patients over 18 years old, patients diagnosed with hypovolemic shock, exclusion criteria: 1) the patient's family was not willing to be sampled, 2) patients who had received intubation therapy, 3 ) conditions that caused pulse oxymetric probe readings disturbed: burns, probe site trauma, finger paint, 4) patients with contraindicated arterial puncture: aneurysms, peripheral artery disease, use of anticoagulants. How to take $\mathrm{SpO} 2$ samples using a Pulse Oximeter (OEM) device that is attached to the thumb, the $\mathrm{PaO} 2$ data collection method is obtained from the results of blood laboratories that are routinely carried out on all hypovolemic shock patients with arterial blood samples. The dependent variable of this study is the Oxygen saturation value on the Pulse Oximeter, while the independent variable is the $\mathrm{PaO} 2$ value on blood gas analysis. The relationship between variables will be assessed by using Pearson's correlation test using SPSS ver 21 software.

\section{RESULT}

This study was conducted on 39 samples that met the inclusion criteria as research subjects, obtained the largest sample of 71.79 percent were patients with grade 3 hypovolemic shock with blood pressure between 71-100 $\mathrm{mmHg}$. The $\mathrm{SpO} 2$ value obtained by using a Pulse Oximeter was 4.6 points lower than the $\mathrm{SaO} 2$ standard on AGDA at all degrees of shock, but the difference was 5.2 in patients with systolic pressure below $100 \mathrm{mmHg}$, and 5.6 points different at systolic pressures below $90 \mathrm{mmHg}$.In the $\mathrm{SaO} 2$ correlation test on pulse oxymetry to $\mathrm{PaO} 2$ in the analysis of blood gases in samples at all degrees of shock there was no correlation, but in samples with systolic pressures below 100 $\mathrm{mmHg}$, namely patients with hypovolemic shock of grade 2 and above using the Pearson test, the correlation value was 0.423 , sig $=0.020$. Whereas in a sample of patients with a systolic pressure below $90 \mathrm{mmHg}$, the Pearson correlation value was obtained of $0.411 \mathrm{sig}=0.041$ (Tables 3 and 4).

\begin{tabular}{|c|c|c|}
\hline Sampel & & $\mathbf{n}(\%)$ \\
\hline Age ( tahun ) & $<20$ & $2(5,1 \%)$ \\
\hline & $20-40$ & $9(23,1 \%)$ \\
\hline & $40-60$ & $16(41,0 \%)$ \\
\hline & $>60$ & $12(30,8 \%)$ \\
\hline & Pria & $24(61,5 \%)$ \\
\hline Gender & Wanita & $15(38,5 \%)$ \\
\hline Systolic Pressure (mmHg) & $41-70$ & $2(5,1 \%)$ \\
\hline & $71-100$ & $28(71,8 \%)$ \\
\hline & $>100$ & $9(23,1 \%)$ \\
\hline SpO2 (\%) & $>93.34$ & $23(58,9 \%)$ \\
\hline & $86,68-93,33$ & $9(23,07 \%)$ \\
\hline & $81-86,67$ & $6(15,3 \%)$ \\
\hline & $<80$ & $1(2,5 \%)$ \\
\hline
\end{tabular}

Table 1:- The frequency distribution of the characteristics of the study sample

\begin{tabular}{|c|c|c|c|c|c|}
\hline & N & Minimum & Maximum & Mean & $\begin{array}{c}\text { Std. } \\
\text { Deviation }\end{array}$ \\
\hline Sistole & 39 & 40,00 & 130,00 & 84,7436 & 16,06355 \\
\hline Heart Rate & 39 & 37,00 & 168,00 & 106,6923 & 25,51795 \\
\hline $\begin{array}{c}\text { Respiratory } \\
\text { Rate }\end{array}$ & 39 & 16,00 & 40,00 & 25,2564 & 6,53218 \\
\hline Sp02 & 39 & 68,00 & 100,00 & 93,0769 & 7,12071 \\
\hline $\mathrm{pH}$ & 39 & 6,94 & 7,67 & 7,3174 &, 15382 \\
\hline $\mathrm{PCO} 2$ & 39 & 13,00 & 50,00 & 28,4641 & 8,81994 \\
\hline $\mathrm{PO} 2$ & 39 & 69,00 & 230,00 & 151,1077 & 42,39059 \\
\hline $\mathrm{HCO} 3$ & 39 & 3,50 & 45,00 & 16,8231 & 9,25323 \\
\hline $\mathrm{BE}$ & 39 & $-29,40$ & 24,60 & $-9,1769$ & 10,67393 \\
\hline $\mathrm{SaO} 2$ & 39 & 79,00 & 100,00 & 97,8462 & 4,65560 \\
\hline
\end{tabular}

Table 2:- Descriptive examination of Vital Sign, AGDA, $\mathrm{SpO} 2$

\begin{tabular}{|ll|l|l|}
\hline & & $\mathrm{Sp02}$ & $\mathrm{PO2}$ \\
\hline $\mathrm{Sp0}$ & Pearson Correlation & 1 &, $423^{\prime}$ \\
2 & Sig. (2-tailed) & &, 020 \\
& $\mathrm{~N}$ & 30 & 30 \\
$\mathrm{PO}$ & Pearson Correlation &, $423^{\circ}$ & 1 \\
2 & Sig. (2-tailed) &, 020 & \\
& $\mathrm{~N}$ & 30 & 30 \\
\hline
\end{tabular}

Table 3:- Pearson correlation between $\mathrm{SpO} 2$ and $\mathrm{PaO} 2$ at blood pressure below $100 \mathrm{mmHg}$

\begin{tabular}{|cl|l|l|}
\hline & & $\mathrm{Sp02}$ & $\mathrm{PO2}$ \\
\hline $\mathrm{S}$ 002 & Pearson Correlation & 1 &, $411^{\circ}$ \\
& Sig. (2-tailed) & &, 041 \\
& $\mathrm{~N}$ & 25 & 25 \\
$\mathrm{P} 02$ &, $411^{\circ}$ & 1 \\
& Pearson Correlation &, 041 & \\
& Sig. (2-tailed) & 25 & 25 \\
& $\mathrm{~N}$ & \\
\hline
\end{tabular}

Table 4:- Pearson correlation between $\mathrm{SpO} 2$ and $\mathrm{PaO} 2$ at blood pressure below $90 \mathrm{mmHg}$

\section{CONCCLUSION}

The higher the degree of hypovolemic shock the greater the difference in Oxygen saturation on the pulse oximeter to the blood gas analysis, so that the pulse oximeter reading will be $4.6-5.6$ points lower than the value it should be. In hypovolemic shock conditions with a systolic pressure below $100 \mathrm{mmHg}$. obtained a correlation of the $\mathrm{SpO} 2$ pulse oximeter value with $\mathrm{PaO} 2$ in the blood gas analysis 


\section{REFERENCES}

[1]. Taghavi S, Askari R. Hypovolemic Shock. StatPearls pub [Internet]. $2020 \quad ; \quad$ Available from: https://www.ncbi.nlm.nih.gov/books/NBK513297/

[2]. Richards J, Wilcox S. Diagnosis And Management Of Shock In The Emergency Department. EB Medicine. 2016; 16 (3): 1-2

[3]. Gayet A, Prietomerino D, Ker K, Shakur H, Ageron FX, Roberts I. Antifibrinolytic Trials Collaboration. Effect of treatment delay on the effectiveness and safety of antifibrinolytics in acute severe haemorrhage: a meta-analysis of individual patient-level data from 40 138 bleeding patients. Lancet. 2018; 391 (10116): 125132.

[4]. Yanda S, Lubis M, Yusroh Y. Comparison of oxygen saturation measured by pulse oximetry and arterial blood gas analysis in neonates. PediatricaIndonesiana. 2004; 43 (11): 211-214

[5]. Wilson J, Cowan H, Lord AJ. Research activeness of pulse oximetry in emergency department patients with severe sepsis and septic shock: a retrospective cohort study. BMC. 2010; 10 (9): 1-6 Patwa A, Shah A. Anatomy and physiology. 